\title{
EMERGING VIRUSES: THE BUNYAVIRIDAE
}

\author{
Richard M. Elliott \\ Institute of Virology, University of Glasgow, Glasgow, Scotland, \\ United Kingdom
}

The family Bunyaviridae is a large but perhaps relatively unfamiliar group of viruses (even among virologists) which contains more than 300 members [reviewed in (1)]. One of the unifying characteristics of these viruses is possession of a tripartite, single-stranded RNA genome. The three genome segments encode four structural proteins, which make up the virus particle, and perhaps one or two nonstructural proteins (accessory proteins required for replication), usually in a negative-sense manner, i.e., anti-message sense. This coding strategy requires that the infecting virus particle contain its own RNAdependent RNA-polymerase to transcribe the genome into mRNAs, which in turn are translated to make new viral proteins. Virus multiplication occurs in the cytoplasm of infected cells and virus particles mature inside the cell by budding primarily at membranes of the Golgi apparatus. Viruses in this family can infect a diverse range of hosts, from mosquitoes to marsupials, and thrips to tomatoes. Several of the Bunyaviridae cause serious diseases in humans, and they are recognized as posing an increasing threat to human health and are good examples of the so-called emerging infections (2).

\section{TAXONOMY AND BIOLOGY}

The family Bunyaviridae is divided into five genera on the basis of serological and biochemical characteristics. Four of these genera-Bunyavirus, Hantavirus, Nairovirus, and Phlebovirus-contain vertebrate-infecting viruses while members

Address correspondence and reprint requests to: Prof. Richard M. Elliott, University of Glasgow, Division of Virology, Church Street, Glasgow G11 5JR, Scotland. Phone: 011-44141-330-4024; Fax: 011-44-141-337-2236; e-mail: r.elliott@vir.gla.ac.uk of the Tospovirus genus infect plants. Members of these genera are thus referred to as bunyaviruses, hantaviruses, nairoviruses, etc. Although all viruses in the family share the less than stringent criteria outlined above, considerable diversity exists at the biological level in terms of hosts and vectors infected and at the molecular level in terms of genome coding and replication strategies (see below). Most of the viruses are transmitted by arthropod vectors (and hence are known as arboviruses, from arthropod borne): in general, bunyaviruses are transmitted by mosquitoes or midges, nairoviruses by ticks, and phleboviruses by sandflies or ticks. Tospoviruses are spread to plants by thrips. Hantaviruses do not have arthropod vectors but are maintained in nature as persistent infections of rodents (hence the term robovirus, from rodent-borne, has been coined) and are transmitted to humans via aerosolized infectious rodent secretions.

\section{GENOME CODING STRATEGIES AND REPLICATION}

Complete genomic RNA sequences for at least one representative of each genus have now been determined, allowing the coding strategies of each segment to be deduced (Fig. 1). The coding of the viral structural proteins is conserved across the family. The L (large) RNA segment encodes the L protein, the RNA polymerase. The $M$ (medium) RNA segment encodes the virion glycoproteins $\mathrm{Gl}$ and G2, which are involved in attachment to the host cell through unidentified receptors and elicit neutralizing antibodies. The $\mathrm{S}$ (small) RNA encodes the nucleocapsid (N) protein, which encapsidates each of the genome RNA segments to form a ribonucleoprotein com- 

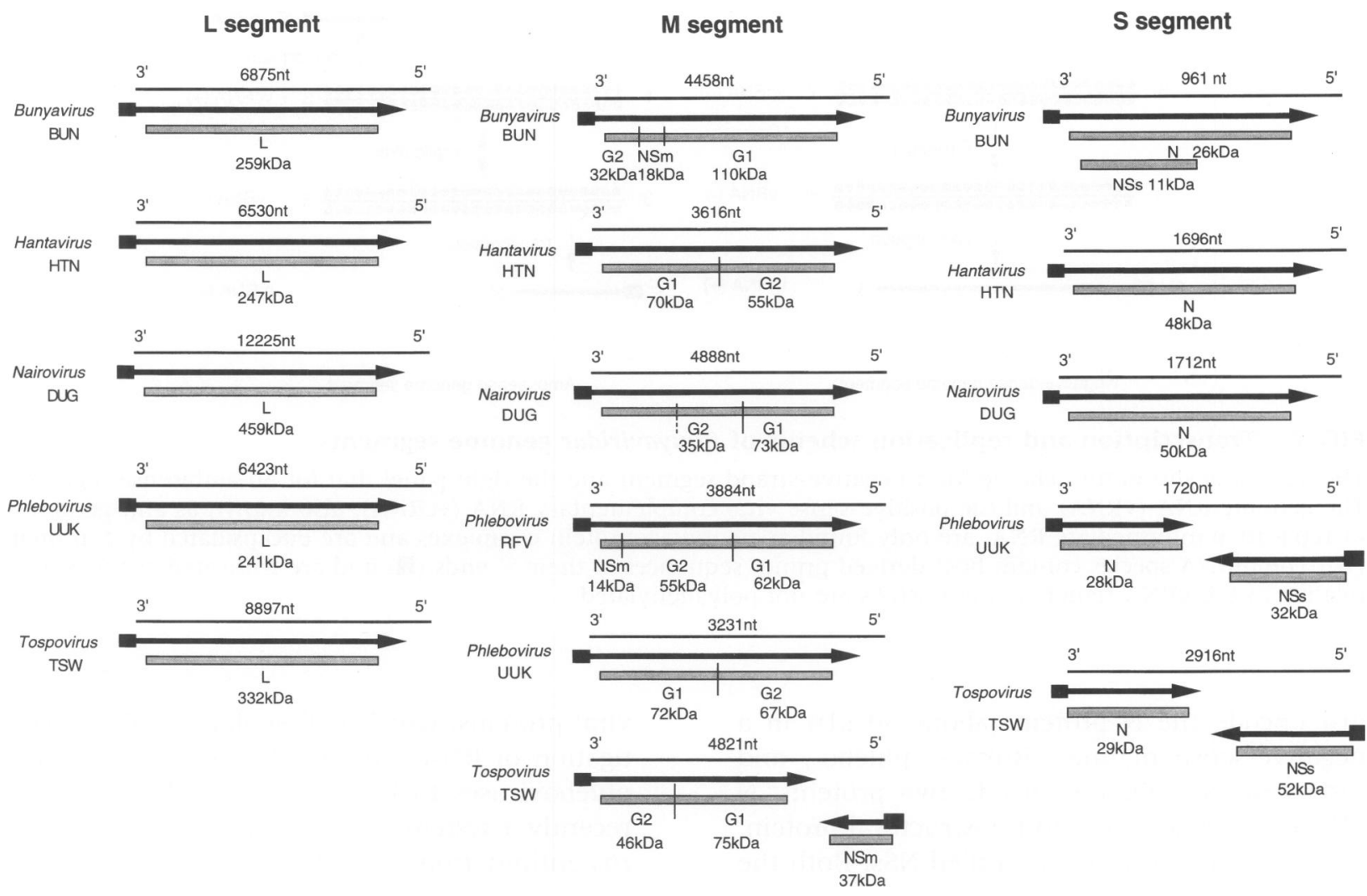

FIG. 1. Coding strategies of Bunyaviridae genome segments

Genomic RNAs are represented by thin lines (the number of nucleotides is given above) and mRNAs are shown as arrows ( $\boldsymbol{\square}$ indicates host-derived primer sequence at $5^{\prime}$ end, indicates $3^{\prime}$ end). Gene products, with their size in kilodaltons, are represented by solid rectangles. Two examples of phlebovirus $M$ segments are given which differ with respect to the presence or absence of NSm. Virus abbreviations: BUN, Bunyamwera; HTN, Hantaan; DUG, Dugbe; RFV, Rift Valley fever; UUK, Uukuniemi; TSW, tomato spotted wilt. [From Elliott, 1996 (1).]

plex (RNP); it is the RNP that is the template for the viral RNA polymerase (3).

All $\mathrm{L}$ proteins are encoded in a negativesense orientation, although the size of the protein varies from about $250 \mathrm{kD}$ for bunya-, hanta-, and phleboviruses to $332 \mathrm{kD}$ for tospovirus and $459 \mathrm{kD}$ for nairovirus. Thus far, only the polymerase domain has been located in these multifunctional $\mathrm{L}$ proteins $(4,5)$, and the overall domain structure, or if additional domains are contained in the larger L proteins, remains to be determined. The $M$ and S segments display various strategies to encode their proteins. Bunya-, hanta-, and phleboviruses encode, in a negativesense manner, a precursor to the structural glycoproteins, and sometimes also a nonstructural protein of unknown function termed NSm, which is probably cotranslationally processed (1). The presence of an NSm protein, and its position in the precursor, differs between genera, and even between viruses in the Phlebovirus ge- nus. The nairovirus glycoprotein precursor is also encoded in a negative-sense orientation, but how the precursor is processed has yet to be resolved (6). Tospoviruses display an intriguing coding strategy in the $M$ segment termed ambisense $(7,8)$ : the structural glycoproteins are encoded as a precursor in a negative-sense manner, but a nonstructural protein (NSm equivalent) is encoded in the same sense as the $5^{\prime}$ end of the viral genomic RNA. However, NSm is not translated from the genome RNA itself (since it is encapsidated by $\mathrm{N}$ protein and hence not available to ribosomes) but from a second subgenomic mRNA (Fig. 2). As the production of this second mRNA requires the onset of genome replication in that it is transcribed from the viral complementary or replicative intermediate RNA, the possession of an ambisense coding strategy affords a degree of temporal regulation to at least some of the viral gene products.

The $S$ segments of hanta- and nairoviruses 


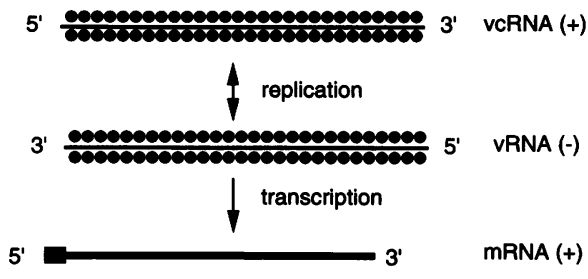

Negative-sense genome segment

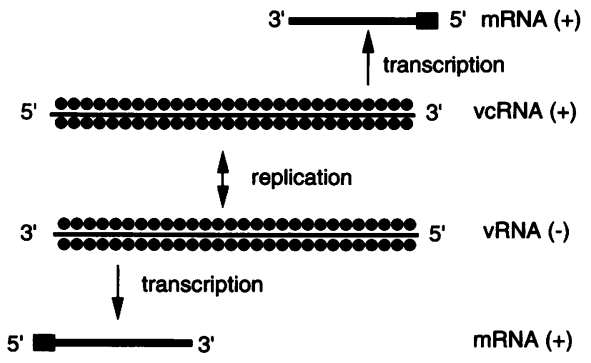

Ambi-sense genome segment

FIG. 2. Transcription and replication scheme of Bunyaviridae genome segments

The left panel shows the scheme for a negative-strand segment and the right panel that for an ambisense segment. The genome RNA (VRNA) and the positive-sense viral complementary RNA (vcRNA), also known as anti-genome or replicative intermediate RNA, are only found as ribonucleoprotein complexes and are encapsidated by $\mathrm{N}$ protein (O). The mRNA species contain host-derived primer sequences at their $5^{\prime}$ ends ( $\square$ ) and are truncated at the $3^{\prime}$ end relative to the vRNA template; the mRNAs are not polyadenylated.

just encode the $\mathrm{N}$ protein (about $50 \mathrm{kD}$ ) in a negative-sense manner. Bunya-, phlebo-, and tospovirus $\mathrm{S}$ segments encode two proteins, $\mathrm{N}$ (25-30 kD) and a second nonstructural protein, also of unknown function, called NSs. Both the bunyavirus proteins are encoded in the same mRNA and are translated as the result of alternative initiation at different AUG codons $(9,10)$. In contrast, the phlebo- and tospovirus $S$ segments are ambisense, with the $\mathrm{N}$ protein encoded in genome complementary RNA while the NSs protein is translated from a subgenomic genome-sense RNA $(11,12)$.

Bunyaviridae transcription resembles that of influenza virus (although occurring in the cytoplasm) in that mRNA synthesis is primed by capcontaining oligonucleotides generated by a viralendonuclease (probably contained in the $\mathrm{L}$ protein) which cleaves host-cell mRNAs, the resulting primers being incorporated into the viral mRNA (3). Hence in Bunyaviridae-infected cells, three (four for ambisense segments) types of RNA representing each segment are found: fulllength negative-sense genomic RNA (vRNA), full-length positive-sense RNA (viral complementary RNA, vcRNA), and positive-sense mRNA which has $5^{\prime}$ nontemplated primer sequences (12-18 bases) and is truncated at the $3^{\prime}$ end (Fig. 2). For the ambisense segments, transcription of both of the subgenomic mRNA species is primed by host-derived oligonucleotides (13). Reverse genetic approaches have been described in which a synthetic viral-like RNA containing a reporter gene can be transcribed and replicated by recombinant transiently expressed viral proteins, which will enable detailed investigation of RNA synthesis by bunyaviruses and phleboviruses to be undertaken $(14,15)$. More recently a system to recover infectious bunyavirus entirely from cloned cDNAs has been developed (16) and this accomplishment opens the way for elucidation of the functions of all the viral proteins, as well as investigation of biological aspects such as tissue tropism, virulence, etc. In the longer term, it may be possible to design modified viruses as potential vaccine strains.

\section{DISEASES CAUSED BY THE BUNYAVIRIDAE}

Viruses in this diverse family cause disease in humans, domesticated animals, and plants, the latter being of considerable economic importance; the most significant pathogens are summarized in Table 1. With regard to human disease, four types of illness are associated with the Bunyaviridae: fever, encephalitis, hemorrhagic fever, and a fatal respiratory syndrome (17). A number of bunyaviruses are associated with febrile illness, often with rash, in humans. As the infections are self-limiting and rarely, if ever, fatal, the overall incidence of bunyavirus infections is unknown. In Europe Tahyna bunyavirus is widely distributed in Germany, Italy, the former Yugoslavia, and the Czech Republic; in Moravia up to $20 \%$ of patients hospitalized with febrile illness are infected with this virus. Oropouche bunyavirus has caused significant epi- 
TABLE 1. Significant pathogens in the family Bunyaviridae, listing diseases, vectors, and distribution

\begin{tabular}{|c|c|c|c|}
\hline Genus/Virus & Host: Disease & Vector & Distribution \\
\hline \multicolumn{4}{|l|}{ Bunyavirus } \\
\hline Oropouche & Human: fever & Midge & S. America \\
\hline La Crosse & Human: encephalitis & Mosquito & N. America \\
\hline Tahyna & Human: fever & Mosquito & Europe \\
\hline Akabane & $\begin{array}{l}\text { Cattle: abortion } \mathcal{G} \\
\text { congenital defects }\end{array}$ & Midge & Africa, Asia, Australia \\
\hline Cache Valley & $\begin{array}{l}\text { Sheep, cattle: congenital } \\
\text { defects }\end{array}$ & Mosquito & N. America \\
\hline \multicolumn{4}{|l|}{ Hantavirus } \\
\hline Hantaan-like viruses & $\begin{array}{l}\text { Human: severe } \\
\text { hemorrhagic fever with } \\
\text { renal syndrome, HFRS } \\
(\mathrm{F}=5-15 \%)\end{array}$ & Field mouse & Eastern Europe, Asia \\
\hline Seoul-like viruses & $\begin{array}{l}\text { Human: moderate HFRS } \\
\qquad(\mathrm{F}=1 \%)\end{array}$ & Rat & Worldwide \\
\hline Puumala-like viruses & $\begin{array}{l}\text { Human: mild HFRS, } \\
\text { nephropathia epidemica } \\
(\mathrm{F}=0.1 \%)\end{array}$ & Bank vole & Western Europe \\
\hline Sin Nombre-like viruses & $\begin{array}{l}\text { Human: hantavirus } \\
\text { pulmonary syndrome } \\
(\mathrm{F}=50 \%)\end{array}$ & Deer mouse & N. and S. America \\
\hline \multicolumn{4}{|l|}{ Nairovirus } \\
\hline $\begin{array}{l}\text { Crimean-Congo } \\
\text { hemorrhagic fever }\end{array}$ & $\begin{array}{l}\text { Human: hemorrhagic } \\
\text { fever }(F=20-80 \%)\end{array}$ & Tick & Eastern Europe, Africa, Asia \\
\hline Nairobi sheep disease & $\begin{array}{l}\text { Sheep, goats: fever, } \\
\text { hemorrhagic } \\
\text { gasteroeneritis, abortion }\end{array}$ & Tick & E. Africa \\
\hline \multicolumn{4}{|l|}{ Phlebovirus } \\
\hline Rift Valley fever & $\begin{array}{l}\text { Human: encephalitis, } \\
\text { hemorrhagic fever, } \\
\text { retinitis (F=1-10\%) } \\
\text { Domestic ruminants: } \\
\text { necrotic hepatitis, } \\
\text { hemorrhage, abortion }\end{array}$ & Mosquito & Africa \\
\hline $\begin{array}{l}\text { Sandfly fever Naples } \\
\text { Sandfly fever Sicilian }\end{array}$ & Human: fever & Phlebotomine fly & Europe, Africa, Asia \\
\hline \multicolumn{4}{|l|}{ Tospovirus } \\
\hline Tomato spotted wilt virus & $\begin{array}{l}>650 \text { plant species: } \\
\text { various symptoms }\end{array}$ & Thrips & Worldwide \\
\hline
\end{tabular}

HFRS, hemorrhagic fever with renal syndrome; F, case fatality.

demics, involving thousands of patients in Brazil, and it is probably widespread throughout South America. Sandfly fever and Rift Valley fever are caused by phleboviruses. The former is a short ( 3 days), nonfatal self-limiting infection. In con- trast, Rift Valley fever displays a variety of disease syndromes ranging from a temporarily incapacitating febrile illness through a retinal disease to, in about $1 \%$ of cases, a fatal hemorrhagic disease. A massive epidemic in Egypt in 
1977 may have affected 200,000 people, and there were about 800 cases of ocular disease and about 600 deaths.

Encephalitis is caused by La Crosse virus infection, and since the discovery of the virus in the early 1960s, the annual reported incidence of La Crosse bunyavirus infection has remained fairly constant at around 100 cases per year (range 42-174), primarily in children and young adults in the midwestern United States. The infection is rarely fatal $(<1 \%)$, although the acute illness is severe, with about half the patients having seizures and about $10 \%$ developing epilepsy or chronic seizures.

Crimean-Congo hemorrhagic fever (CCHF) is a particularly severe tick-borne disease whose symptoms are horrifyingly similar to those of other hemorrhagic fevers such as Lassa fever or Ebola fever. The case fatality in tick-acquired disease is around $20 \%$, but it is significantly higher in nosocomial infections acquired from viremic blood, perhaps because the inoculum dose is higher. CCHF occurs in Africa, Asia, and eastern Europe.

In terms of human disease, the most important members of the Bunyaviridae are the hantaviruses, which cause hemorrhagic fever with renal syndrome (HFRS) and hantavirus pulmonary syndrome (HPS). There are about 200,000 hospitalized cases of HFRS reported each year, with about half of these in China. There are three forms of HFRS-severe, moderate, and mild (Table 1)-caused by different hantaviruses, with fatality rates ranging from less than $0.1 \%$ for the Puumala-like viruses to $15 \%$ for Hantaan-like viruses. HFRS cases predominantly occur in Asia, the Balkans, and Scandinavia. In 1993 novel hantaviruses were identified in the Americas as responsible for cases of a severe respiratory disease, HPS, or "Four Corners disease," with about $50 \%$ mortality. The severity of the disease prompted much investigation into the ecology and epidemiology of hantaviruses in the Americas, and now more than 250 cases of HPS have been reported and many other new hantaviruses have been described (18).

\section{CONCLUSIONS}

The large number of viruses in the family Bunyaviridae is taken as evidence of their vast evolutionary potential (19), and together with their capacity for dramatic antigenic shift through genome segment reassortment (1), warrants their continual surveillance and further study. Relatively few vaccines for members of the Bunyaviridae have been developed. A live attenuated vaccine against Rift Valley fever virus is available whereas most other vaccines are inactivated viral preparations. Clearly there is much scope for the development of novel vaccines through molecular biological techniques for the hazardous members of the group.

\section{REFERENCES}

1. Elliott RM (ed). (1996) The Bunyaviridae. Plenum Press, New York.

2. Morse SS. (1995) Factors in the emergence of infectious diseases. Emerg. Infect. Dis. 1: 7-15.

3. Kolakofsky D, Hacker D. (1991) Bunyavirus RNA synthesis: Genome transcription and replication. Curr. Top. Microbiol. Immunol. 169: 143-160.

4. Jin H, Elliott RM. (1992) Mutagenesis of the $\mathrm{L}$ protein encoded by Bunyamwera virus and production of monoclonal antibodies. J. Gen. Virol. 73: 2235-2244.

5. Muller R, Poch O, Delarue M, Bishop DHL, Bouloy M. (1994) Rift Valley fever virus L segment: Correction of the sequence and possible functional role of newly identified regions conserved in RNA-dependent polymerases. J. Gen. Virol. 75: 1345-1352.

6. Marriott AC, El Ghorr AA, Nuttall PA. (1992) Dugbe nairovirus M RNA: Nucleotide sequence and coding strategy. Virology 190: 606-615.

7. Bishop DHL. (1986) Viruses with ambisense RNA genomes. In: Notkins AL, Oldstone MBA (eds). Concepts in Viral Pathogenesis II, Springer-Verlag, New York, pp. 32-39.

8. Kormelink R, de Haan P, Meurs C, Peters D, Goldbach R. (1992) The nucleotide sequence of the M RNA segment of tomato spotted wilt virus, a bunyavirus with two ambisense RNA segments. J. Gen. Virol. 73: 2795-2804.

9. Fuller F, Bhown AS, Bishop DHL. (1983) Bunyavirus nucleoprotein, $\mathrm{N}$, and a nonstructural protein, NSs, are coded by overlapping reading frames in the S RNA. J. Gen. Virol. 64: 1705-1714.

10. Elliott RM, McGregor A. (1989) Nucleotide sequence and expression of the small (S) RNA segment of Maguari bunyavirus. Virology 171: 516-524.

11. Ihara T, Akashi H, Bishop DHL. (1984) Novel 
coding strategy (ambisense genomic RNA) revealed by sequence analysis of Punta Toro phlebovirus S RNA. Virology 136: 293-306.

12. de Haan P, Wagemakers L, Peters D, Goldbach R. (1990) The S RNA segment of tomato spotted wilt virus has an ambisense character. J. Gen. Virol. 71: 1001-1007.

13. Simons JF, Pettersson RF. (1991) Host-derived $5^{\prime}$ ends and overlapping complementary $3^{\prime}$ ends of the two mRNAs transcribed from the ambisense $S$ segment of Uukuniemi virus. J. Virol. 65: 4741-4748.

14. Dunn EF, Pritlove DC, Jin H, Elliott RM. (1995) Transcription of a recombinant bunyavirus RNA template by transiently expressed bunyavirus proteins. Virology 211: 133-143.

15. Lopez N, Muller R, Prehaud C, Bouloy M. (1995) The L protein of Rift Valley fever virus can rescue viral ribonucleoproteins and transcribe synthetic genome-like RNA molecules. J. Virol. 69: 3972-3979.

16. Bridgen A, Elliott RM. (1996) Rescue of a segmented negative-strand RNA virus entirely from cloned complementary DNAs. Proc. Natl. Acad. Sci, U.S.A. 93: 15400-15404.

17. Swanepoel R. (1995) Bunyaviridae. In: Zuckerman AJ, Banatvala JE, Pattison JR (eds). Principles and Practice of Clinical Virology, 3rd ed. John Wiley \& Sons, Chichester, pp. 517-554.

18. Schmaljohn CS, Hjelle B. (1997) Hantaviruses: A global disease problem. Emerg. Infect. Dis. 3: 95-104.

19. Elliott RM. (1995) Evolution of Bunyaviridae. In: Gibbs AJ, Calisher $\mathrm{CH}$, Garcia-Arenal F (eds). Coevolution of Viruses and Their Hosts. Cambridge University Press, Cambridge, pp. 321-337. 